\title{
As contribuições do lúdico no processo de desenvolvimento das crianças com síndrome de Down na educação infantil
}

\author{
Rosana Carla Gonçalves Gomes Cintra* \\ Allyne Nunes de Oliveira** \\ Elaine Cristina Freitas Veiga ${ }^{* * *}$
}

\begin{abstract}
Resumo
O presente estudo tem por objetivo analisar os subsídios da ludicidade no processo de ensino e aprendizagem de crianças com Síndrome de Down, com enfoque principal nas contribuições da dança. Uma das melhores formas de estimulação para as crianças com síndrome de Down é através das atividades e brincadeiras lúdicas que envolvam as diversas linguagens artísticas como a dança, a música, o teatro e o movimento. A inclusão na rede de ensino é um direito da pessoa com deficiência, sendo assegurado por meio da Lei $n^{\circ} 7.853 / 89$, que decreta a obrigatoriedade do fornecimento de vagas na rede regular de ensino para crianças deficientes. Para tanto adotamos a abordagem qualitativa com levantamento bibliográfico, utilizando como base teórica os autores Vygotsky (2001), Silva (2005), Coutinho (2001) e o Referencial Curricular para a Educação Infantil (1998), tendo como viés teórico-metodológico a perspectiva histórico-cultural. A partir da pesquisa realizada concluímos que a inclusão e o desenvolvimento de crianças com síndrome de Down é de suma importância em ambientes lúdicos, sendo possível trabalhar atividades que estimule seu desenvolvimento de forma prazerosa, sem ser cansativo para a mesma e ao mesmo tempo estimulando sua autonomia.
\end{abstract}

Palavras-chave: educação inclusiva; Síndrome de Down; educação infantil.

\section{The contributions of ludic in development of children with down syndrome in early childhood education}

\begin{abstract}
This study aims to analyze the playfulness of subsidies in the teaching and learning of children with Down syndrome, with main focus on dance contributions. One of the best forms of stimulation for children with Down syndrome is through the activities and playful banter involving the variety of artistic expressions such as dance, music, theater and movement. The inclusion in the school system is a right of people with disabilities, being carried out by way of Law No. 7,853 / 89 decrees the mandatory supply of vacancies in mainstream education for disabled children. For both, we chose a qualitative research with literature, using as theoretical basis the authors Vygotsky (2001), Silva (2005), Coutinho (2001) and the Curriculum Reference for Early Childhood Education (1998), with the theoretical and methodological bias in cultural-historical perspective. The survey led us to conclude that the inclusion and the development of children with Down syndrome is of paramount importance in recreational environments, and can work activities that stimulate their development in a pleasant way, without being tiring for the same and at the same time stimulating their autonomy.

Keywords: inclusive education; Down's Syndrome; early childhood education.

\section{Introdução}

O presente estudo surgiu de questionamentos referentes às leituras relacionadas à área da Educação Especial, com foco na aprendizagem das crianças com síndrome de Down, buscando entender as suas especificidades, percorrendo os primeiros registros de crianças com síndrome de Down até a atualidade. A partir desses questionamentos procuramos entender como se dá o desenvolvimento dessa criança, que, por conta do excesso cromossômico, acaba tendo características específicas.

A partir daí, discutimos brevemente a

educação inclusiva como lei e direito de todas as crianças com deficiência, sem exceção. No Artigo 208, inciso III da Constituição Federal, especifica a obrigatoriedade do Atendimento Educacional Especializado (AEE) para deficientes, preferencialmente na rede regular de ensino.

A educação infantil é um direito da criança e dever do Estado; assim sendo, a instituição educativa deve estar organizada para atender às crianças com síndrome de Down, promovendo a inclusão dessas crianças na turma, proporcionando momentos lúdicos que incentivem o desenvolvimento da autonomia. Em 1998, foi publicado o Referencial Curricular para a Educação

\footnotetext{
* Universidade Federal de Mato Grosso do Sul - UFMS - Campo Grande. Endereço eletrônico: rosana.cintra@ufms.br ** Universidade Federal de Mato Grosso do Sul - UFMS - Campo Grande. Endereço eletrônico: allyne_no@ hotmail.com *** Universidade Federal de Mato Grosso do Sul - UFMS - Campo Grande. Endereço eletrônico: elainefreitasveiga@ hotmail.com
} 
Infantil (RCNEI), que tem como objetivo nortear a prática do professor da educação infantil, fazendo parte dos documentos elaborados pelo Ministério da Educação e do Desporto, os Parâmetros Curriculares Nacionais.

O terceiro volume do RCNEI traz as múltiplas linguagens, como o movimento, o teatro e a música, que devem ser contemplados nas práticas pedagógicas da educação infantil. A partir dessas linguagens buscamos entender a importância que a ludicidade tem no desenvolvimento de crianças com síndrome de Down, direcionando nesse primeiro momento da pesquisa nosso olhar para a dança, a qual está inteiramente relacionada ao movimento, porém não uma dança técnica visando à formação de um profissional, mas à linguagem da dança como uma forma de expressão dessas crianças a partir do corpo.

Para esta pesquisa adotamos a abordagem qualitativa, por meio de estudos bibliográficos sobre educação infantil, dança e síndrome de Down, com o objetivo de elucidar as questões levantadas pelo grupo, tendo como viés teórico-metodológico a perspectiva histórico-cultural vygotskyana. Utilizamos como base teórica os autores Silva (2005), Coutinho (2001), Cintra (1999) e o Referencial Curricular para a Educação Infantil (1998) e Vygotsky (2001), que versam sobre a temática abordada neste artigo.

Nós, educadores, devemos repensar a nossa prática pedagógica cotidianamente; para isso contamos com uma importante base científica, com estudos na área da infância e da inclusão que servem como alicerce na sala de aula, perseguindo sempre uma melhor prática pedagógica.

\section{Síndrome de Down}

Os primeiros trabalhos científicos relacionados às crianças e adultos com síndrome de Down ocorreu apenas no século XIX, mas foram encontrados registros de pessoas com a síndrome antes de Cristo.

Schwartzman (1999) situa que podemos encontrar referências às pessoas com síndrome de Down na cultura dos Olmecas, no período de 1500 a.C. até $300 \mathrm{~d}$. C, pois, a partir de achados arqueológicos, percebeu-se que essa civilização representava, em suas esculturas $e$ desenhos, pessoas com traços faciais peculiares às que apresentam essa síndrome (SILVA, 2005, p. 77).

Foram encontradas diversas esculturas de pessoas com síndrome de Down na cultura Olmeca; essas pessoas eram consideradas deusas, acreditavam que elas eram concebidas através de um cruzamento entre mulheres com uma idade mais avançada com o Jaguar.

A Síndrome de Down é decorrente de uma alteração genética ocorrida durante a gestação. $O$ nome surgiu a partir da descrição de John Langdon Down medico inglês que descreveu, em 1866, pela primeira vez as características de uma criança com esta síndrome. A Síndrome de Down também pode ser chamada de trissomiado 21, que é um acidente genético que causa a síndrome. Ocorre quando exatamente no par cromossômico 21 existem três cromossomos em vez de dois, daí a terminologia de trissomiado 21 (LEFEVRE, 1988 apud ZANIN; CEBALOS; MAZARO, 2012, p. 01).

Em 1866, o Dr. John Langdon Down fez o reconhecimento clínico desse defeito genético, diferenciando as pessoas com síndrome de Down de outras que possuíam outro tipo de deficiência intelectual.

A síndrome se dá na concepção; trata-se da primeira anomalia detectada na espécie humana, é congênita, o que resulta entre outras características em deficiência intelectual. Segundo Silva (2005), a presença de 01 cromossomo a mais nas células de um indivíduo acarreta um variável retardo no desenvolvimento físico, funcional e intelectual. Quando esse cromossomo extra localiza-se no par de número 21 , este passa a ser, também, uma característica da pessoa com síndrome de Down.

Os cromossomos recebidos na hora da fecundação são metade passados pelo espermatozoide e a outra metade pelo óvulo. Se alguma célula vier com 24 cromossomos e outra com 23, levará à formação de uma célula com 47 cromossomos. A síndrome ocorre por uma meiose falha do espermatozoide ou do óvulo, o que resulta no excesso de cromossomos, que é a causa da síndrome de Down.

As características no caso da síndrome de Down são causadas pela trissomia do par de cromossomos 21, que pode ocorrer de três formas, sendo a forma mais frequente a trissomia livre ou 
simples: ao invés de ter dois cromossomos, o indivíduo possui três, causando-lhe várias especificidades físicas e deficiência intelectual. Outro tipo de trissomia é a translocação, onde o cromossomo 21 está geralmente unido ao cromossomo 14; suas consequências são semelhantes às da trissomia simples e, se ao fazer o exame de cariótipo, for constatada a translocação no bebê síndrome de Down, o exame também terá que ser feito pela família, pois servirá para avaliar se poderão ter filhos com trissomia. O mosaicismo, consiste em uma mistura, uma parte das células possui a trissomia do 21 e outras não, algumas ficam com 46 e outras com 47cromossomos, distribuídas em proporções diferentes pelo organismo (BONFIM apud ORNELAS; SOUSA, 2001, p. 78-79).

A síndrome de Down influencia a formação do corpo, além do prejuízo intelectual, acarretando em algumas características comuns.

Fisicamente, os indivíduos com síndrome de Down costumam nascer menores e mais leves do que os outros bebês. Em geral são bochechudos, (devido à flacidez muscular), apresentam hipotonia e têm olhos amendoados relativamente distantes um do outro. Alguns têm prega epicântica, ou seja, um excesso de pele no canto interno dos olhos. Os braços e as pernas são curtos. Possuem também As orelhas implantadas um pouco abaixo do normal, e o nariz, pequeno. O dedo mínimo se mostra ligeiramente curvo. As mãos são menores e gordas, com a palma atravessada por uma única prega transversa. Nos pés, é comum encontrarmos uma distância anormalmente grande entre o primeiro e o segundo dedo.

Como já citado por conta do defeito cromossômico nas células, ocorre, também, atraso intelectual.

Com deficiência mental geralmente
moderada, hipotonia muscular
generalizada, pouca coordenação dos
movimentos, língua protusa, respiração
bucal, cardiopatias (em 40\% dos casos),
fala tardia, sensibilidade a infecçoes,
hiperextensibilidade articular, frouxidão
ligamentar da primeira e da segunda
vértebra e outros (BONFIM apud
ORNELAS; SOUSA, 2001, p. 79).

Devido à hipotonia, as crianças com a síndrome possuem grande dificuldade de deglutir e sugar e também são sonolentas. Com o passar do tempo e com a estimulação adequada, a hipotonia tende a diminuir.

Devemos salientar que, embora essas sejam todas características da síndrome de Down, nem todas as crianças desenvolvem todas essas características específicas, podendo ter apenas algumas delas.

A idade cronológica de pessoas com síndrome de Down é diferente da idade funcional, o que faz com que sejam vistas como crianças. $\mathrm{Na}$ síndrome de Down o desenvolvimento e a aprendizagem dos indivíduos sofrem interferências devido ao comprometimento intelectual,que ocorre devido ao excesso de cromossomos; eles também possuem singularidades biológicas, psicológicas e sociais que se refletem na qualidade de vida da pessoa acometida e da família. O desenvolvimento dos indivíduos com a trissomiado par 21está intimamente relacionado à motivação e ao incentivo que recebem, sobretudo nos primeiros anos de vida, sendo também determinantes a educação e o ambiente nos quais estão inseridos desde o seu nascimento.

[...] o desenvolvimento da criança com $S D$, nos cinco primeiros anos de vida, está baseado em alguns pressupostos correlacionados ao desenvolvimento considerado típico. De acordo com esses autores, o desenvolvimento motor mostra-se atrasado, da mesma forma que as demais áreas do desenvolvimento; a presença de graus importantes de hipotonia muscular seguramente contribui para este atraso motor. Afirmam ainda que todos os marcos de desenvolvimento motor tendem a surgir mais tarde, com a idade média para sentarse sozinho ocorrendo por volta dos nove meses (6-16 meses); ficar em pé com apoio por volta dos 15 meses (8-25 meses) $e$ andar por volta dos 19 meses (13-48 meses) (ANHÃO, 2009, p. 19).

Outro ponto de suma importância é termos sempre em mente que, apesar das diversas semelhanças físicas entre as crianças com síndrome de Down, elas são diferentes entre si, cada uma com suas particularidades, gostos, tempo de aprendizagens, desenvolvimento se vivências que as tornam diferentes umas das outras.

Os pais podem influenciar negativamente no processo de desenvolvimento das crianças com síndrome de Down por meio da superproteção e com isso focam suas atenções na deficiência, impossibilitando as crianças de se desenvolverem, de interagirem com o mundo em busca de autonomia. Segundo Silva (2002), as habilidades de autonomia pessoal e social proporcionam melhor qualidade de vida, pois favorecem a relação, a 
independência, interação, satisfação pessoal e atitudes positivas.

A estimulação essencial e o trabalho conjunto com pais e professores podem resultar em melhorias no desenvolvimento físico e cognitivo das crianças.

\section{A educação infantil, o lúdico e a criança com síndrome de Down}

A criança sempre existiu no mundo, mas a infância só foi realmente reconhecida no século XVIII. Como afirmam Sarmento e Pinto Barbosa (1997 apud BARBOSA, 2006, p.73): “com efeito, crianças existiram desde sempre, desde o primeiro ser humano, e a infância como construção social".

As crianças não eram vistas como hoje em dia, com particularidades que as diferenciam das pessoas mais velhas; anteriormente elas eram tratadas como pequenos adultos, pois, depois que deixavam de usar o cueiro, começavam a utilizar roupas idênticas a eles. Esse modo de vestir as crianças foi retratado em diversas pinturas do século XVI e XVII, como a pintura de Catherine-Eleonore de Bethisy (1707-67), que é retratada em que as vemos com longos vestidos.

Infância, como categoria social que assinala os elementos de homogeneidade deste grupo minoritário, e as crianças, como referentes empíricos cujo conhecimento exige a atenção aos fatores de diferenciação e heterogeneidade, afigura-se não como um redundância ou sutileza analítica, mas como uma necessidade incontornável na definição de um campo de estudos ou investigação (SARMENTO; PINTO, 1997 apud BARBOSA, 2006, p. 73).

Só depois de muito tempo a criança foi reconhecida como um ser pertencente à sociedade, com suas particularidades e com seus próprios direitos. O reconhecimento da sua infância, da importância de vivências culturalmente ricas nesse período, de suas particularidades e direitos passou a se demandar também uma instituição que desenvolvesse todos esses quesitos.

[...] movimento da sociedade civil $e$ de órgãos governamentais para que o atendimento às crianças de zero a seis anos fosse reconhecido na Constituição Federal de 1988. A partir de então, a educação infantil em creches e pré-escolas passou a ser, ao menos do ponto de vista legal, um dever do Estado e um direito da criança (artigo 208, inciso IV). O Estatuto da Criança e do Adolescente, de 1990, destaca também o direito da criança a este atendimento (BRASIL, 1998, p. 13).

A Educação Infantil passou a ser um direito da criança e obrigação do Governo. O direito ao atendimento em creches e pré-escolas está amparado pela Constituição de 1988 em seu Artigo 208, IV - atendimento em creche e pré-escola às crianças de zero a seis anos de idade" (inciso IV do art. 208 da Constituição Federal), com direito a profissionais bem formados e ambientes que favoreçam a descoberta da identidade e da autonomia da criança, passando a ser pensado também na educação das crianças deficientes. A educação inclusiva tem sido muito debatida nos últimos anos, ao se pensar em um ambiente que respeite as particularidades de todos que estão inseridos ali.

A Constituição Federal de 1988estabelece o direito das pessoas com deficiência de receberem educação, preferencialmente, na rede regular de ensino, com o objetivo de garantir o direito à educação inclusiva na rede regular de ensino.

A síndrome de Down é uma forma de vida, e não uma doença; as crianças com essa síndrome têm a capacidade de fazer tudo que as pessoas com desenvolvimento típico fazem, só levam um tempo um pouco maior para desenvolver algumas habilidades específicas, mas são totalmente capazes, o que faz com que a estimulação seja essencial em seu desenvolvimento desde os primeiros meses de vida.

Outros comprometimentos que afetam a criança Down e implicam dificuldades ao desenvolvimento da aprendizagem são: alterações auditivas e visuais, incapacidade de organizar atos cognitivos e condutas, debilidades de associar e programar sequências. Estas dificuldades ocorrem principalmente porque a imaturidade nervosa e não mielinização das fibras pode dificultar funções mentais como: habilidade para usar conceitos abstratos, memória, percepção geral, habilidades que incluam imaginação, relação espacial, esquema corporal, habilidade no raciocínio (ZANIN; CEBALOS; MAZARO, 2012, p. 01).

Uma das melhores formas de estimulação para as crianças com síndrome de Down é através das brincadeiras e atividades que envolvam as diversas linguagens artísticas como a dança, música, 
teatro; podemos trabalhar atividades que desenvolvam a criança de uma forma prazerosa, sem ser exaustiva para ela.

Segundo Vygotsky (2001), as brincadeiras com palavras, brincadeiras com ritmos, sons... etc.: em todas essas confusões observa-se uma ordem ideal. Nessa loucura existe um sistema. Ao incorporar a criança num mundo de pernas para o ar, nós não só não prejudicamos o seu trabalho intelectual como, ao contrário, contribuímos para ele, uma vez que na própria criança existe a aspiração a criar para si esse mundo às avessas, para assim afirmar com mais segurança nas leis que regem o mundo real. Esses pequenos absurdos seriam perigosos para a criança se bloqueassem as reais autênticas interações de ideias e objetos. Mas, além de não as bloquearem, as promovem, ressaltam, destacam, reforçam (e não enfraquecem) na criança a sensação da realidade.

É através das brincadeiras que a criança com síndrome de Down, assim como todas as outras, vão descobrindo o mundo, tendo relações com os outros. Para Vygotsky, só nos desenvolvemos através das relações sociais, em contato com o outro.

O processo de desenvolvimento humano, numa perspectiva sócio-histórica, é percebido como sendo constituído a partir das constantes interações com o meio social. Portanto, o desenvolvimento é socialmente constituído. Inicialmente, este ocorre no nível social, ou seja, a partir das relações entre as pessoas, no nivel interpsicológico, e, só posteriormente, no nivel individual ou intrapsicológico (VYGOTSKY, 1978 apud DANIELS, 2001, p. 89).

$\mathrm{O}$ ato de brincar tem uma função social, cultural. No ato de brincar as crianças entram em contato com um mundo novo, novos objetos, novas possibilidades, sentimentos; o ato de brincar, apesar de parecer simples, é algo muito complexo, que exige muito da criança. Esse contato com outros indivíduos e com o mundo é fundamental para que a criança com síndrome de Down desenvolva sua identidade, sua autonomia e descubra o mundo a sua volta.

As brincadeiras também proporcionam o contato com as regras e o esperar a vez, lembrando que as regras devem ser respeitadas por todos.
A cultura lúdica é, então, composta de certo número de esquemas que permitem iniciar a brincadeira, já que se trata de produzir uma realidade diferente daquela da vida quotidiana: os verbos no imperfeito, as quadrinhas, os gestos estereotipados do início das brincadeiras compõem assim aquele vocabulário cuja aquisição é indispensável ao jogo (BROUGÈRE, 1998, p. 01).

Como já dito, o ato de brincar é cultural, as brincadeiras se diferem de região para região, as brincadeiras mudam conforme o local onde a criança, Down ou não, está inserida, assim como outros fatores, como o gênero, idade, um local que propicie à criança criar sua autonomia enquanto brinca.

Trabalhar com atividades lúdicas na sala de aula é de extrema importância para o desenvolvimento das crianças como a dança e a música, que são essenciais. Para uma boa atividade, necessitamos de um bom planejamento que inclua toda a turma, sempre respeitando as diferenças, buscando atividades que desafiem as crianças continuamente, buscando o melhor delas, permitindo que as crianças tenham voz na brincadeira, tomando decisões e seguindo as regras.

\section{As contribuições da dança no ensino das crianças com Síndrome de Down: movimento e dança na educação infantil}

Com a obrigatoriedade da oferta da educação infantil na educação básica, foi elaborado, em 1998, o Referencial Curricular para a Educação Infantil (RCNEI).

Atendendo às determinações da Lei de Diretrizes e Bases da Educação Nacional (Lei 9.394/96) que estabelece, pela primeira vez na história de nosso país, que a educação infantil é a primeira etapa da educação básica, nosso objetivo, com este material, é auxiliá-lo na realização de seu trabalho educativo diário junto às crianças pequenas (BRASIL, 1998, p. 06).

O objetivo do RCNEI é auxiliar o professor da educação infantil na elaboração de planejamentos que assegurem o direito das crianças a seu desenvolvimento integral, proporcionando contato 
com a realidade social e cultural.

[...] as instituições de educação infantil devem favorecer um ambiente físico e social onde as crianças se sintam protegidas $e$ acolhidas, e ao mesmo tempo seguras para se arriscar e vencer desafios. Quanto mais rico e desafiador for esse ambiente, mais ele lhes possibilitará a ampliação de conhecimentos acerca de si mesmas, dos outros e do meio em que vivem (BRASIL, 1998, p. 15).

O RCNEI traz o movimento, a música, o teatro e outras formas de linguagens artísticas que proporcionam um enriquecimento cultural para as crianças. Um dos desafios é fazer isso valer nas instituições, que muitas vezes dão valor apenas à aprendizagem da leitura e da escrita, esquecendo-se das múltiplas linguagens com que as crianças devem ter contato.

As instituições educacionais infantis desconsideram as cem linguagens das crianças atribuindo os mais diversos motivos. Sendo assim é necessária a produção de conhecimento sobre as diversas infâncias e suas constituições (COUTINHO, 2001, p. 04).

O movimento do corpo está presente a partir do nascimento nas pessoas, desde o ato de pegar um objeto, engatinhar ou através do movimento também nos comunicamos; quando o bebê fica inquieto, se mexendo muito, é uma forma de ele demonstrar que algo o está incomodando.

O Referencial Curricular para a Educação Infantil (RCNEI) traz o movimento $\mathrm{e}$ as suas contribuições para o desenvolvimento da criança.

O movimento é uma importante dimensão do desenvolvimento e da cultura humana. As crianças se movimentam desde que nascem, adquirindo cada vez maior controle sobre seu próprio corpo e se apropriando cada vez mais das possibilidades de interação com o mundo. Engatinham, caminham, manuseiam objetos, correm, saltam, brincam sozinhas ou em grupo, com objetos ou brinquedos, experimentando sempre novas maneiras de utilizar seu corpo e seu movimento. Ao movimentar-se, as crianças expressam sentimentos, emoções e pensamentos, ampliando as possibilidades do uso significativo de gestos e posturas corporais.
O movimento humano, portanto, é mais do que simples deslocamento do corpo no espaço: constitui-se em uma linguagem que permite às crianças agirem sobre o meio físico e atuarem sobre o ambiente humano, mobilizando as pessoas por meio de seu teor expressivo (BRASIL, 1998, p. 15).

Através da dança trabalhamos todas as formas de movimentação do corpo, expressamos nossos sentimentos, exercitamos a memorização, a atenção e a socialização entre as crianças. A dança é um dos meios mais eficazes de se trabalhar o movimento na educação infantil. $O$ espaço da educação infantil deve proporcionar todos esses momentos de aprendizado.

A dança é um ótimo aliado para a criança com síndrome de Down no seu desenvolvimento. Um dos maiores obstáculos quando a dança é utilizada em sala de aula é o professor, quando não permite que as crianças se expressem livremente com seu corpo. O professor deve dar liberdade às crianças para que elas possam se movimentar, conhecer seu corpo, sem o oprimir com um arquétipo.

Uma maneira bem eficiente de se trabalhar a dança com os portadores de SD é utilizála de forma educacional recreativa, sendo uma excelente forma de estabelecer a saúde, aptidão física, autoconfiança, equilíbrio emocional, integração social, entre outros benefícios por ser um método que não se preocupa com a técnica, e sim, propõe que as pessoas adaptem os exercícios ao seu dia-a-dia, seu meio, proporcionando liberdade de movimentos (LIMA; BOSQUES, 2010, p. 01).

Elegendo a aprendizagem como processo principal do desenvolvimento humano, Vygotsky (1984) afirma que: "a zona de desenvolvimento proximal é o encontro do individual com o social, sendo a concepção de desenvolvimento abordada não como processo interno da criança, mas como resultante da sua inserção em atividades socialmente compartilhadas com outros".

Lima e Bosques (2010) trazem uma ótima explicação das vantagens da dança na Educação Infantil, as contribuições que a expressão corporal tem a oferecer para as crianças com a síndrome, proporcionando um rico momento de interação social, descoberta do corpo e autonomia, entre outros.

A dança é uma das melhores formas de 
expressar o que se está sentindo e ajuda a criança a suplantar a timidez e a interagir com os seus colegas; há um desempenho positivo quando é permitido às crianças criarem passos, tendo a liberdade de se expressarem através dos movimentos de seu corpo, trazendo um melhoramento no desenvolvimento motor.

Assim, a pessoa com síndrome de Down necessita para seu desenvolvimento da possibilidade de convívio social, pois é através da mediação entre seus pares que se promove a concepção de consciência corporal, desenvolvimento cognitivo, coordenação motora e, consequentemente, melhor qualidade de vida e movimento, pois, como observa Vygotsky, só nos tornamos humanos em convivência com outros humanos.

\section{Considerações finais}

A síndrome de Down é o defeito genético mais comum atualmente. Ao longo dos anos de estudos relacionados à síndrome de Down, o conceito que se tem sobre esse defeito genético mudou consideravelmente. Acreditava-se que uma pessoa com síndrome de Down não seria capaz de executar trabalhos simples de casa e muito menos que pudesse aprender como uma criança dita normal, mas através de estudos foi possível provar que pessoas com síndrome de Down têm total capacidade de aprender, precisando apenas de incentivo e um tempo um pouco maior. Hoje a criança com síndrome de Down tem direito à inclusão nas instituições educativas públicas de ensino. Atualmente podemos ver jovens e adultos com Down ingressando no mercado de trabalho e universidades.

Ao longo do artigo buscamos abordar a importância da inclusão na educação infantil, focando nas crianças com síndrome de Down. É na educação infantil que a criança com síndrome de Down poderá ter contato com diversas linguagens artísticas, brincadeiras, as quais proporcionarão o seu desenvolvimento, além de possibilitar o desenvolvimento de suas habilidades através das atividades lúdicas.

A partir da inclusão é possível difundir o universo da arte sem limites, para que a cultura e o entretenimento façam cada vez mais parte da vida das crianças, estabelecendo diálogos entre a dança e a educação formal, de modo a subsidiar na teoria e na prática o ensino da dança. Além disso, o professor deve buscar desenvolver no aluno a consciência corporal e aprimorá-lo enquanto instrumento de expressão, comunicação, percepção, e não somente de reprodução, utilizando assim a dança como linguagem significativa, plena de objetivos pedagógicos.

Portanto, entendemos a dança como produto humano que se constitui e se constrói nas interações sociais dentro de um processo histórico-cultural, promovendo manifestações que desenvolvam percepção, imaginação e criação, processos que humanizam o ser humano.

Quanto à importância da dança para a educação, acreditamos na necessidade de um trabalho consciente e interdisciplinar que contemple as demais práticas da escola, a ampliação da formação do professor em relação à abordagem corporal, além de formação prática, visto que a dança constitui uma atividade importante dentro da escola, que visa à formação de pessoas atuantes, autônomas, conscientes e humanas.

Cabe ao professor propiciar um ambiente rico em motivação e possibilidades de cognição e movimento, como por exemplo, materiais como tecidos, bambolês e bolas, diversas texturas e formas para incentivar e aguçar a percepção, o equilíbrio, a criatividade, a memorização de sequências, a contagem rítmica, a coordenação motora, o equilíbrio, a postura, a autoestima, os limites, o respeito ao corpo do outro e ao próprio corpo. Ao criar composições com vários movimentos e interligá-los, as crianças se sentem atores do processo, e não apenas plateia.

\section{Referências}

ANHÃO, P. P. G. O processor de interação social na inclusão escolar de crianças com Síndrome de Down em educação infantil. 2009. 88p. Dissertação de Mestrado, Programa de Pós-Graduação em Saúde na Comunidade, Faculdade de Medicina de Ribeirão Preto, Universidade de São Paulo, Ribeirão Preto, 2009.

BARBOSA, Maria Carmem Silveira. Por amor $e$ por força: rotinas da educação infantil. Porto Alegre: Artmed, 2006.

BRASIL. Ministério da Educação e do Desporto. Secretaria de Educação Fundamental. Referencial curricular nacional para a educação infantil. Brasília: MEC/SEF, 1998.

BRASIL. Constituição da República Federativa do Brasil. Brasília, 1988. 
BROUGÈRE, G. A criança e a cultura lúdica. Rev. Fac. Educ. vol.24 n. 2 São Paulo July/Dec. 1998.

CINTRA, Rosana Carla Gonçalves Gomes. Educação Especial X Dança: um diálogo possível. Campo Grande. Editora UCDB, 1999.

CINTRA, R.C.G. G; PELICIONE, D. A dança e o lúdico: atividades da criança no processo ensino/ aprendizagem. In: Tempos e contratempos no espaço da educação infantil. Campo Grande MS. 2009. Editora UFMS.

CEBALOS, N. M; MAZARO, R. A; ZANIN, M. A importância do lúdico para crianças com Síndrome de Down. Disponível em: < http://www.efdeportes.com/efd168/universo-ludicopara-criancas-com-sindrome-de-down.htm> Acesso em: 31 jul de 2014.

COUTINHO, Ângela Maria Scalabrin. Infância $e$ diversidade: as culturas infantis. In: 24a Reunião Anual de Pós-graduação e Pesquisa em Educação, 2001, Caxambu - MG. Anais da $24^{\text {a }}$ Reunião anual da ANPED. Petrópolis: Vozes, 2001. p. 1-9.

DANIELS, Harry (org). Uma introdução a Vygotsky. São Paulo: Loyola, 2001.

LIMA, Luciana Jardim de; BOSQUE, Ronédia Monteiro. A contribuição da dança para o desenvolvimento integral dos alunos do grupo de dança $d a \quad A P A E-A P$. Disponível em: $<$ http://www.rexlab.ufsc.br:8080/more/formulario10 $>$. Acesso em: 02 maio 2013.

MORANDI, C. A Dança e a Educação do cidadão sensivel. In: STRAZZACAPPA, M. Entre a arte e a docência: A formação do artista da dança. Campinas: Papirus, 2006.

ORNELAS, M. A; SOUSA, C. A contribuição do profissional de educação física na estimulação essencial em crianças com Síndrome de Down. Revista da Educação Física. Maringá, v. 12, n. 1, $2001 . \quad$ Disponível em: <http://www.periodicos.uem.br/ojs/index.php/RevE ducFis/article/view/3779-10611-1.pdf> Acesso em: 27 jul de 2014.

SILVA, K. S. de B. P. da. O papel das interações no processo de inclusão de crianças com Síndrome de Down. 2005. Dissertação (Mestrado em Educação) - Universidade Federal do Rio Grande do Norte. Natal.

VYGOTSKY, L.S. A formação social da mente. São Paulo: Martins Fontes, 1984.

VYGOTSKY, L. S. Psicologia da arte. São Paulo: Martins Fontes, 2001.

\section{Sobre as autoras}

Rosana Carla Goncalves Gomes Cintra é Professora Associada 3 do Centro de Ciências Humanas e Sociais CCHS da Universidade Federal de Mato Grosso do Sul UFMS. Professora de graduação, curso de Pedagogia e pesquisadora-orientadora do Mestrado em Educação (PPGEdu) do CCHS, em Campo Grande, na Linha de Pesquisa Educação, Psicologia e Prática Docente. Líder do Grupo de Estudos e Pesquisas em Educação Especial e Múltiplas Linguagens GEPEMULT, cadastrado no CNPq, e também, coordenadora do Projeto de Extensão Unika Dança UFMS- Escola de Formação de Bailarinos e Cia de Dança, atua como diretora, coreógrafa e professora desde 2005. Coordenou a Especialização em Educação infantil no campus de Coxim CEEI/UFMS/MEC e a Turma 1 do Curso de Especialização em Docência na Educação Infantil CEEI/UFMS/MEC, de Campo Grande.

Allyne Nunes de Oliveira é graduanda em Pedagogia - Licenciatura pela UFMS - Campo Grande, membro do Grupo de Estudos e Pesquisas em Educação Especial e Múltiplas Linguagens - GEPEMULT. Bolsista de Iniciação Científica do CNPq 2014-2015.

Elaine Cristina Freitas Veiga é graduanda em Pedagogia - Licenciatura pela UFMS - Campo Grande, membro do Grupo de Estudos e Pesquisas em Educação Especial e Múltiplas Linguagens - GEPEMULT. Bolsista de Iniciação Científica do CNPq 2014-2015.

Recebido em agosto de 2014.

Aprovado em maio de 2015. 